\title{
Report from the Inauguration Ceremony of the academic year 2019/2020 at the President Stanisław Wojciechowski State University of Applied Sciences, Kalisz, 4 October 2019
}

\author{
Kinga Janik-Koncewicz \\ Health Promotion Foundation, Nadarzyn, Poland \\ European Observatory of Health Inequalities, the President Stanisław Wojciechowski State University of Applied Sciences \\ in Kalisz, Poland
}

ADDRESS FOR CORRESPONDENCE: Kinga Janik-Koncewicz, Health Promotion Foundation, 51 Mszczonowska St., 05-830 Nadarzyn, Poland, phone: +48 2237800 22, e-mail: biuro@promocjazdrowia.pl

The President Stanisław Wojciechowski State University of Applied Sciences in Kalisz inaugurated the new academic year on 4 October 2019. It was also a celebration of the $20^{\text {th }}$ anniversary of the University. The inauguration brought together distinguished guests, scientific and medical experts, local and national authorities, as well as students, academics, and administration staff. The first part of the ceremony was held in the University Collegium Novum Hall and was continued in the Wojciech Bogusławski Theatre in Kalisz. It was a fortunate occasion to matriculate new students, summarise the University's achievements during the 20 years of its activity, award deserved University employees for their exceptional achievements, and to establish the World Institute of Family Health as a new University unit. As is traditional, the ceremony commenced with the song Laudate Dominum performed by the University choir.

Professor Andrzej Wojtyła gave a welcome speech and greeted all guests and participants. He presented a short history of the University and its main achievements. The President Stanisław Wojciechowski State University of Applied Sciences was established on 15 July 1999. It has been developing rapidly from the start and still aims to transform into an academy. The mission of the University is to educate young people with adjustment for current national social and economic needs. The main areas of interest are technical, medical, and economic sciences. The University aspires to develop research activities and international scientific collaboration. Currently, it provides 24 fields of studies, has approximately 3,000 new students, 18,000 graduates, and around 300 academics. Professor Wojtyła listed, among others, successes of the European Observatory of Health Inequalities and the Journal of Health Inequalities. He recalled the Calisia World Conference on Family Health which took place in June 2019 [1] and mentioned that this year the Journal of Health Inequalities was included in the list of scientific journals published by the Ministry of Science and Higher Education. After Professor Wojtyła's speech, he awarded those employees who had rendered great service to the University in recent years and matriculated first-year students.

In the next part of the ceremony, the founding deed of the World Institute of Family Health was signed by the Rector Andrzej Wojtyła, Professor Andrey Bazylevych, President of the World Federation of Ukrainian Medical Associations, Professor Otis Brawley, John Hopkins University, USA, Professor Leonardo Chavane, Eduardo Mondlane University, Mozambique, and Professor Witold Zatoński, President of the Health Promotion Foundation, Poland (Photo 1). The deed referred to the $20^{\text {th }}$ anniversary of the founding of the University and expressed the signatories' desire that the World Institute of Family Health should tackle global family health problems and conduct scientific research to solve these problems.

Next, Professor Witold Zatoński gave a laudation in honour of the keynote speaker, Professor Otis Brawley. Professor Zatoński introduced Professor Brawley's profile: an American physician and Bloomberg Distin- 
guished Professor of Oncology and Epidemiology at Johns Hopkins University, who served as Chief Medical and Scientific Officer and Executive Vice President of the American Cancer Society between 2007 and 2018. His work focused on prevention, diagnosis, and treatment of cancer, especially prostate cancer. He is the author of scientific publications, chapters, and books, the director of large scientific programmes in the United States. He is an educator, promoter, and leader in cancer research and health disparities worldwide. A summary of Professor Brawley's presentation is presented in Box 1.

In the second part of the inauguration ceremony, Professor Zatoński introduced Professor Leonardo Chavane, an experienced public health specialist with a documented

BOX 1. Summary of Professor Otis Brawley's keynote lecture at the Inauguration Ceremony

\section{Cancer and the family}

The diagnosis of cancer, or indeed the diagnosis of any serious illness, has tremendous effects on the patient and his/her family and friends. The newly diagnosed patient goes through a number of changes after the diagnosis. They can experience sadness, anxiety, anger, and a sense of hopelessness. This can be of significant concern to family members, and they can have the same feelings. Family and friends are affected throughout all phases of the patient's illness. The effects during end of life are, of course, obvious, but there are also effects in survivorship. The importance of open communication throughout the course of illness with the healthcare team cannot be overemphasised.

While all healthcare providers must be attentive to the emotional support of the patient and family, the involvement of counsellors or social workers trained in mental health psychology can be incredibly beneficial and is very appropriate. In recent years the palliative care movement has filled this need. Palliative care is an interdisciplinary approach to specialised medical and nursing care for people with chronic conditions and their families. In many countries palliative care is a separate medical specialty that involves teams of physicians, psychologists, and social workers. It focuses on providing relief from symptoms, pain, and physical and mental stress of chronic disease at any stage of illness. The goal is to improve quality of life of both the person and their family. There is clear evidence that palliative care can improve the patient's quality of life, and in some very serious illnesses it has even been shown to increase survival.

Family members may feel a number of complex feelings and emotions. It is best that healthcare providers, be we doctors, nurses, social workers, or other providers, try to understand these changes so that we can help the patient and those who support the patient. It is also helpful in talking to the palliative care team and other providers who will counsel the patient and family. The expression of feelings and needs by the patient and family should be encouraged. Open communications can aid in growing healthy relationships supportive to the patient during challenging times.

\section{Within a marriage or long-term relationship}

For the married patient or the patient in a long-term relationship, the illness can strengthen the relationship, but it can also create new problems and worsen old problems within the relationship. Within a marriage or long-term relationship, the patient who has always been in charge may have trouble accepting a subservient role as they are unable to do usual chores and responsibilities. The partner taking on new responsibilities can be overwhelmed. They can also become overly protective or controlling. This can lead to frustration and resentment in the partner and guilt and frustration in the patient. Caregivers frequently suffer from stress.

The patient may have difficulty asking for help with basic activities of daily life such as hygiene or getting dressed. The spouse or partner also may not realise this and may misinterpret the patient's behaviours. There are also emotional needs; both partners can need reassurance that they are still loved. Expression of needs to the partner can be difficult. It is often easier to talk to a healthcare professional, who will not be overwhelmed, than to talk to a partner or relative. Sexual health and intimacy can also be affected by the disease. The patient can experience depression, nausea, and other physical and emotional problems that may lower sex drive and can also make intercourse difficult or painful. Both partners may feel anxious or reluctant to discuss these issues.

Cancer can change the couple's hopes and dreams for retirement, travel, and among younger patients even plans for parenthood. Couples should be encouraged to work together and talk about re-evaluating priorities and set short-term goals.

\section{Adult family and friends}

The patient should try to stay involved, and family and friends can often best be supportive by trying to keep the patient involved in social activities with family and friends. It is suggested that one person from the family be designated as in charge of communicating medical updates to the rest of the family and friends.

One should expect relationships to change. Some will grow more distant due to the previous painful experiences with disease, especially if the person has dealt with the same disease. Others will be frightened as the illness brings their mortality clearer. Some will not talk as they do not know what to say. Some may become overbearing, and boundaries may need to be set.

\section{Children}

There is a tendency to want to protect children from news of a serious illness. It is, however, important to talk openly with children about the diagnosis. Indeed, avoiding the topic is bad. It can lead the perceptive child to sense a problem and become confused and 
fearful. When talking to young children one should focus on things pertinent to them such as the change in availability or change in appearance of the patient.

One should expect changes in the child as they adjust to the patient's diagnosis and treatment. Young children may become overly clingy or impulsive. Older children such as teenagers may become angry or distant. One should be patient and encourage children to ask questions and talk about the feelings. Balancing the patient's needs and the children's needs can be a challenge. A person living with cancer is physically and emotionally exhausted. In the case of adult children taking care of a mother or father with cancer, this change can be difficult for both the parent as well as children. Roll reversal creates significant stress for the caregiver and the patient.

\section{The child with cancer}

The child with cancer is a very special problem. There can be tremendous stress upon family members. The child can even believe that they are responsible for the stress and feel guilt. The effects of the illness can vary widely in relationships. Different families have different ways of communicating, coping, and reacting in a crisis.

Otis W. Brawley, MD, MACP, FASCO, FACE Bloomberg Distinguished Professor Johns Hopkins University Baltimore, MD, USA

Supplementary slides are available in Webappendix 1 at the journal's website: https://www.termedia.pl/Journal/Journal_of_Health_Inequalities-100.

history of working in the public health area, a leader in the implementation of quality of care of maternal, neonatal and reproductive health, as well HIV/AIDS programmes (see Professor Chavane's biographical note in Box 2). Professor Chavane presented a lecture on the role of families in the health status and reproductive health of women and adolescents in Mozambique (see: Role of families in the health status: the case reproductive health of women and adolescents in Mozambique on pp. 137-140) [2].

In the last part of the ceremony, Professor Zatoński, on behalf of the Health Promotion Foundation, awarded Professor Andrey Bazylevych, President of the World Federation of Ukrainian Medical Associations, Professor Otis Brawley, John Hopkins University, USA, and Professor Leonardo Chavane, Eduardo Mondlane University, Mozambique, with the Foundation's Golden Honorary Awards (Photo 2). These scientists were awarded in recognition of their services to people's health and their concern for the quality of life of us all, for their longterm friendship and support without which the Foundation's activity would have never been so successful, and for teaching society that defending health is both a good investment and necessary for a long and enjoyable life.

The Health Promotion Foundation's Golden Lungs have been awarded since 1996 to individuals who made a significant contribution to building stronger public health, promoting healthy lifestyles, and improving the quality of life in Poland, across Europe, and globally. The Golden Lungs represent the Health Promotion Foundation's appreciation of their work, which is often characterised by great personal commitment and by little consideration of personal gain. The award is shaped in the form of lungs which, although small in size, symbolise our great gratitude. By awarding a group of laureates every year, the Foundation has fostered a network of friends and collaborators who have stood with us for over two decades in our efforts to build a healthier society. The ceremony closed with a concert of Justyna Szafran, the Polish actress, singer, and performer of poetry set to music.

\section{DISCLOSURE}

The author reports no conflict of interest.

\section{References}

1. Janik-Koncewicz K. Report from the Calisia World Conference on Family Health, Kalisz, Poland, 9-10 June 2019. J Health Inequal 2019; 5 (1): 2-10.

2. Chavane $\mathrm{L}$. The role of families in population health: the case of reproductive health of women and adolescents in Mozambique. J Health Inequal 2019; 5 (2): 137-140.

\section{BOX 2. Professor Leonardo Chavane's biographical note}

Leonardo Chavane, PhD, Mozambican Medical Doctor, Public Health Specialist with a master's degree in Public Health. He graduated in 1997 the Eduardo Mondlane University, Mozambique and has worked within public health at the district, provincial, and national level coordinating health service delivery including maternal and child health services. Between 2008 and 2012 he was Deputy National Director of Public Health at the Ministry of Health of Mozambique, responsible for maternal and child health programmes. Since 2012, he has been National Senior Advisor for the Maternal and Child Integrated Program. Since 2014 he has been Project Director for the Maternities Centres of Excellence Project. 


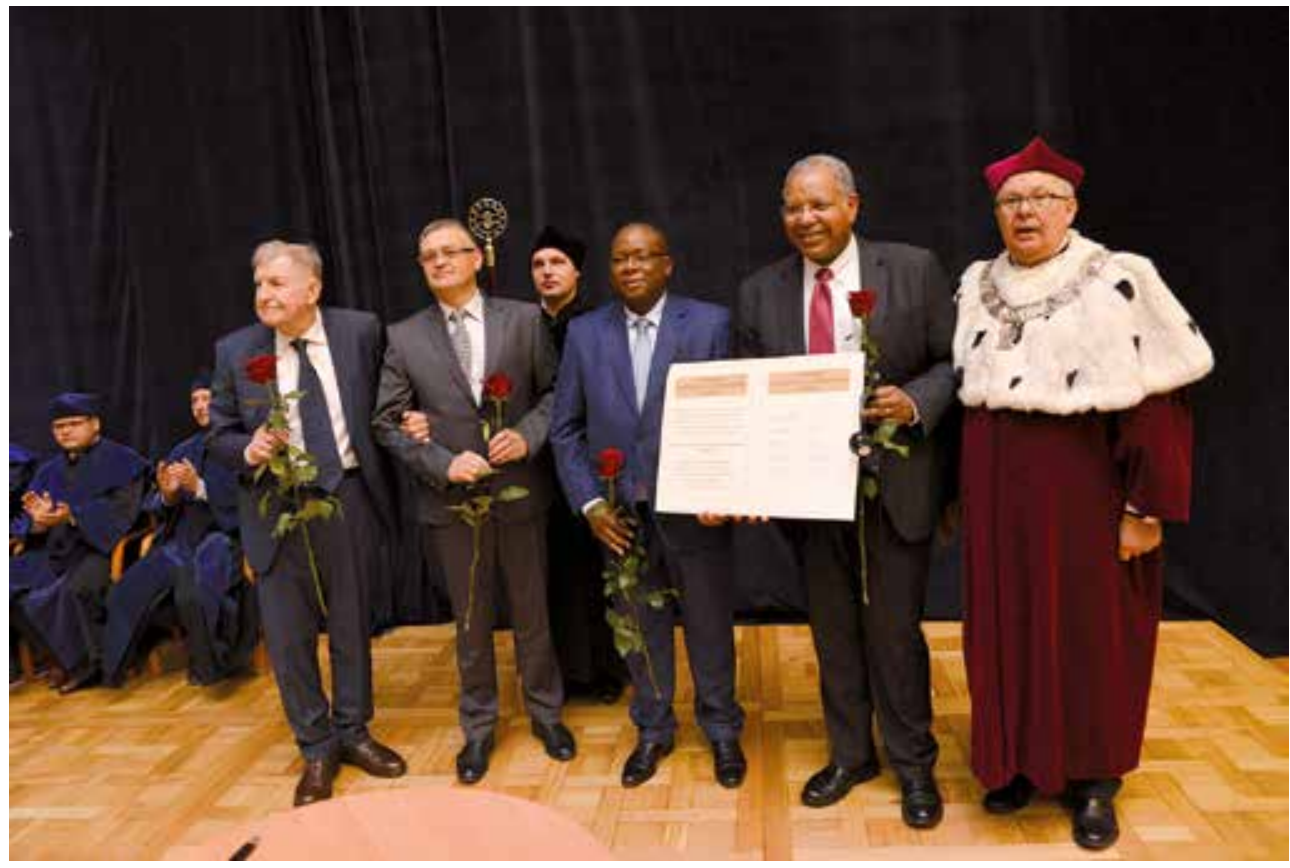

FIG. 1. Signatories of the founding deed of the World Institute of Family Health

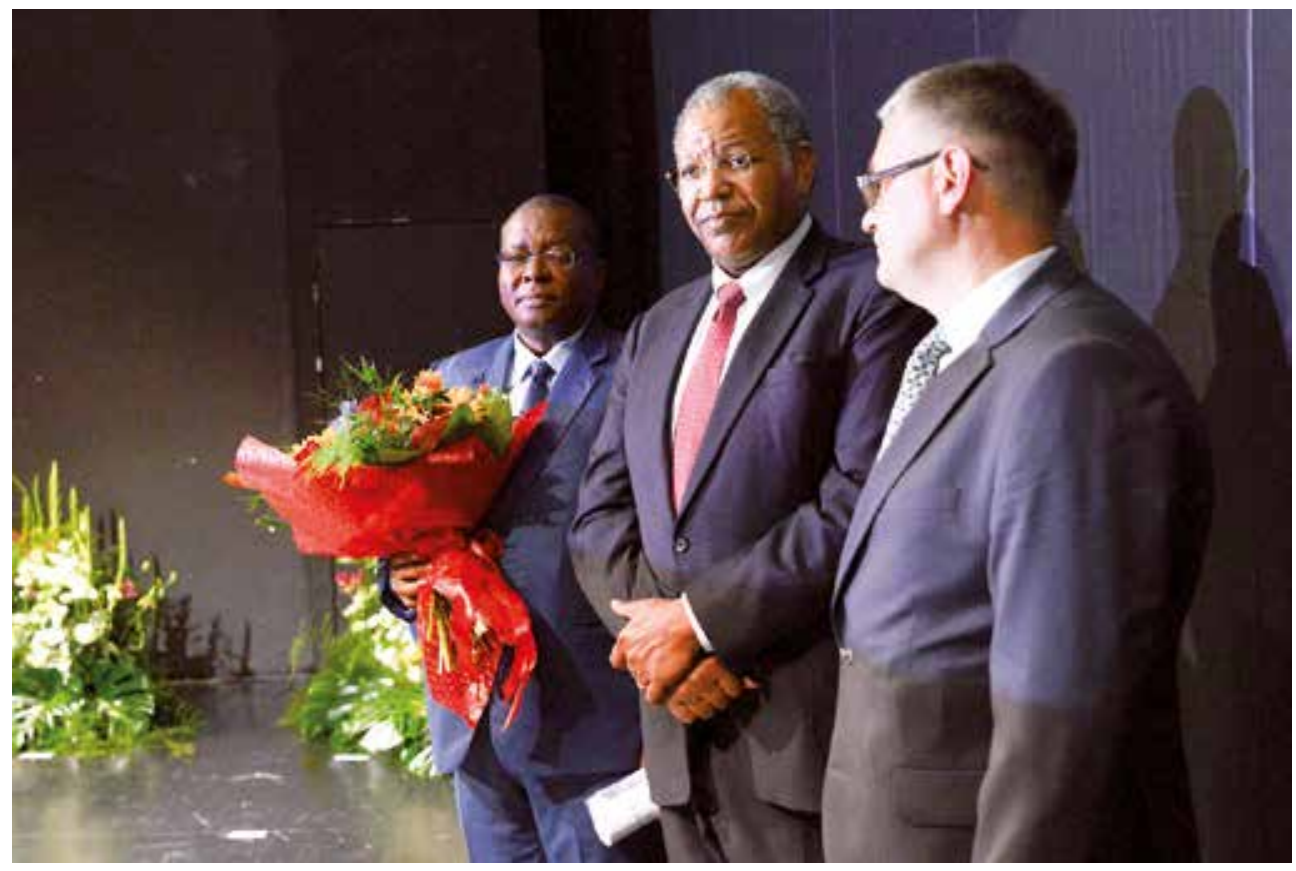

FIG. 2. Laureates of the Health Promotion Foundation's Honorary Award 